\title{
Comparison of clinical instructors' teaching behaviors as perceived by themselves with those assessed by their students in the clinical setting
}

\author{
Hala Gabr Mahmoud*
}

\begin{abstract}
The clinical education is considered as the heart of the nursing education. It remains the single most important resource in the development of competent, capable, and caring nurses. It prepares the students for their professional role and provides them with opportunity to apply knowledge, skills, and concepts in the clinical settings. Most importantly, clinical instructors' behaviors in the clinical area play an important part in the learning process of the student. There are few studies that determine and evaluate what constitutes effective teaching behaviors of clinical instructors in the clinical area. Hence, the present study aimed at comparing clinical instructors' teaching behaviors as perceived by themselves with those assessed by their students and also using qualitative analysis to determine positive and negative students' comments for clinical instructor behaviors in the clinical setting. The study was conducted at Faculty of Nursing at Mansoura University. Two groups of subjects were included in the present study; clinical instructors group ( $n=62)$ and nursing students group $(n=120)$. Two questionnaire sheets were used for data collection; clinical instructors' questionnaire and student's questionnaire that were developed by researcher based on reviewing literature. The third part of student's questionnaire included open ended questions to establish positive and negative clinical instructors' as perceived by student encountered in clinical training. A major finding of this study was that there was a statistical significance difference between clinical instructors' teaching behaviors as perceived by themselves with those assessed by their students in the clinical setting. At the end of the study, recommendations were given that clinical instructor should offer information and positive feedback in the directions of students, being accessible and also encourage student's creative thinking and freedom in discussion.
\end{abstract}

\section{NTRODUCTIION}

Recent years have seen international efforts both to support and monitor the clinical education of student nurses and derive more meaningful and sensitive clinical learning indices $^{(1)}$. Clinical education plays a crucial role in undergraduate nursing program. Not only it provide opportunities for students to apply the theory learned in the classroom, but also is a socialization process which students are inducted into the practices, expectations, and real-life work environment of the nursing profession ${ }^{(2)}$.Clinical training is considered as indispensable and very important part of professional nursing education. It offers students the opportunity to develop their clinical skills. In the Facultyies of Nursing, clinical education is composed of nearly half of the requirements of the nursing programme and all students must be able to successfully and competently pass the clinical component

\footnotetext{
*Nursing Administration Department. Faculty of Nursing, Mansoura University
} 
of the course before they can professionally practice nursing ${ }^{(3,4)}$.

The aim of clinical education is to develop the students' professional skills and knowledge needed in life-long learning, critical thinking to create self-confidence as a nurse, and to ensure that the nurse is able to make her own decisions independently. That means if the student nurse can apply the Theoretical knowledge that she has acquired to the real environment can she provide the desired level of patent care. In other words, nursing can only be undertaken through clinical practice, which is in effect learning through experience $^{(5)}$.

The quality of the student-teacher interaction in the clinical field can either facilitate or hinder the students' integration of theory to practice. It has been postulated that clinical instructor must possess effective clinical teacher characteristics if he wants to facilitate students' entry and learning in a multifaceted world of clinical practice ${ }^{(\bullet)}$.

The clinical instructor can be defined as a person who teaches nursing practice to undergraduate students and responsible for the bulk of student nurses education ${ }^{(7)}$. Moreover, Walts ${ }^{(8)}$ identified the clinical instructor as a registered nurse employed by the university who has completed at least a baccalor degree in nursing and teaches undergraduate nursing students in the clinical settings.

The clinical instructors' teaching behaviors in the clinical area are widely debated in the literature. An interpretive research approach by Duffy \& Watson ${ }^{(9)}$, was used to understanding of the behaviors of the clinical instructor in the clinical area. They reported five themes of clinical instructors' behaviors as being an advisor, being a supporter, being a regulator, being an interpreter, and being a net worker behavior. They concluded that the clinical instructor have a multifaceted behavior which includes providing advice and support to trained staff and students, regulating professional standards, interpreting assessment documentation and networking with clinical staff. Most importantly, clinical instructors' behaviors in the clinical area play 
an important part in the learning process of the student. Assessment of clinical instructors' behaviors in the clinical setting by their students is in an important issue in nursing education. A large percentage of students' time spent contact with clinical instructor in clinical setting. Therefore, it is important to define a method to assess clinical instructors' behaviors by their students in clinical setting..$^{(10)}$

Effective clinical teaching in nursing education has received significant attention over the years. Early manuscripts and researches focused on how to teach issues for nursing faculty and less attention given to students' perspectives of effective clinical teaching behaviors. More contemporary discussions and empirical analyses are targeting to identify what makes a nursing educator as a good clinical instructor ${ }^{(11)}$.

Faculty often awaits the arrival of student evaluations with apprehension, and teaching performance is a particular concern for novice educators $^{(12)}$. Furthermore, student feedback has motivated and empowered faculty staff to improve their teaching performance ${ }^{(13)}$. Faculty considers student evaluations an important indicator of effective teaching. Student comments constitute important elements of nursing faculty staff evaluation to improve quality in nursing education programs ${ }^{(\mathbf{1 4})}$.

Peer, self, administrative, and student evaluations, in addition to student outcomes are the most frequent sources of data used to document faculty teaching effectiveness. Wolf et al.,(14) results indicate that faculty staff strengths behaviors included being a knowledgeable and strategic teacher, creating a positive learning environment, demonstrating professionalism, displaying scholarly traits, and being supportive. While weaknesses behaviors included poor delivery of content, acting disorganized, being inaccessible, displaying weak teaching skills, being dishonorable, being unprofessional, and displaying negative traits.

Many universities have reliable and valid instruments for evaluating faculty members in classrooms and do not have concerned to assess clinical instructor 
behaviors in clinical settings. There are few studies that define and assess teaching behaviors of clinical instructor in the clinical area.

\section{Aim of the study}

The present study aimed at comparing the clinical instructors' teaching behaviors as perceived by themselves with those assessed by their students in the clinical setting.

\section{MATERIAL AND METHODS}

\section{Setting:}

The study was conducted at Faculty of Nursing at Mansoura University. It includes eight scientific nursing departments namely; Adult Nursing, Pediatric Nursing, Obstetrics Nursing, Critical Nursing, Psychiatric Nursing, Community Nursing, Geriatric Nursing, and Nursing Administration. All the mentioned departments were included in the present study.

Subjects: Two groups of subjects were included in the present study:
Clinical instructors group: The total number of nursing faculty members at Faculty of Nursing, Mansoura University was 94 staff members, they comprise of one professors, two assistant professors, 15 lecturers, 28 assistant lecturers, and 48 demonstrators. Only 20 assistant lecturers and 42 demonstrators were willing to participate in the present study. They supervise nursing students and actively involved in conducting clinical teaching for student nurses at least one year in the clinical settings.

\section{Nursing students group}

The total number of nursing students of

The total number of nursing students of academic year 2006-2007 was 1225 . They comprise 300 (24.49\%) in the first year, 325 $(26.53 \%)$ in the second year, $393(32.08 \%)$ in the third year, and 207 (16.90\%) in the fourth year. Of these a random stratified sample of 120 nursing students, enrolled in the Faculty of Nursing from four levels of academic year, first, second, third, and fourth at the time of the 
study of the academic year 2006-2007 was included in the study.

A random sample of 120 students, representing approximately $10 \%$ of the targeted group stratified by academic year. This approach respects the weights of different years. The ratio of $2: 1$ of the two groups of the study sample maintains a good power of the statistical test.

\section{Tool of data collection}

The data were collected using two questionnaire sheets. They were developed by the researcher based on reviewing literature $(6,10,11,14)$ which include:

1- Clinical instructors' questionnaire sheet:

This first questionnaire sheet aimed at reflecting clinical instructor's perceptions of the effective clinical teaching behaviors in the clinical setting. This questionnaire was divided into three parts:

The first part: It was used to identify demographic characteristics of the clinical instructors as age, educational qualification, years of experience, nursing department, and marital status.

The second part: It includes 50 items related to the clinical instructor's points of view of the effective clinical teaching behaviors in the clinical setting. These items were grouped under five categories based on Beitz and Wieland ${ }^{(11)}$; professional competence (13 items), relationship with students (15 items), teaching ability (8 items), personality traits ( 6 items), and evaluation (8 items).

The responses of the participants were measured on a three point Likert scale that ranges from highly important to not important. Accordingly, each response was assigned a score from 1 point for highly important to 3 points for not important.

The third part: It consists of six questionnaires related to the factors that effect nursing clinical instructors' behaviors in the clinical setting. The clinical instructors were asked to rank these factors according to their priority. 


\section{2- Students' questionnaire sheet:}

The second questionnaire sheet reflects the clinical teaching behaviors of the clinical instructors in the clinical setting as assessed by undergraduate nursing students.

The first part: It was used to identifying demographic characteristics of the nursing students, academic level, and clinical nursing department.

The second part: It includes 50 items related to clinical teaching behaviors of clinical instructor in the clinical setting that was grouped under five categories that were determined by Beitz and Wieland(11); and these items of this part are the same items of the second part of the clinical instructors' questionnaire sheet.

In this part of the questionnaire, the students were asked to assess their clinical instructors in the clinical setting by using a four point Likert scale that ranges from always to never. Accordingly, each response was assigned a score from 1 (always), 2 (sometimes), 3 (rarely), and 4 (never).
The third part: It include open ended questionnaire to establish positive and negative clinical instructors' behaviors as perceived by student encountered during clinical training. In this part, qualitative comments were thematically analyzed and organized according to positive and negative clinical teaching behaviors. It was categorized according to the five subscales that determining by Beitz and Wieland ${ }^{(11)}$, namely professional competence, relationship with students, teaching ability, personality traits, and evaluation.

\section{Methods of data collection}

1- An official approval was obtained from the Dean of the Faculty of Nursing at Mansoura University.

2- $\quad$ The developed questionnaire was tested for content validity by five experts from both Faculty of Nursing, Alexandria and Mansoura Universities.

3- The questionnaire was also tested for its reliability using test-retest. This was done through administration of the tool to twenty students of the Faculty of 
Nursing, Mansoura University. After analysis of data obtained from their responses to the items of the questionnaire used, a re-test was used to compute the correlation between the responses of the items of the first and second time using one month interval. The structured questionnaire reliability scored $84 \%$ where $p<0.05$ which means that questionnaire used is a reliable one

4- A pilot study was performed on 20 students to test the wording and clarity of the questions and to estimate the necessary time to fill the questionnaire. The necessary modifications were accordingly performed.

5- The questionnaire sheets were distributed to respondents. Each respondent took 15-20 minutes to complete the questionnaire.

6- The study questionnaire was distributed late by the end of the second semester (April, 2007) of the academic year 20062007, prior the final exam.

\section{RESULTS}

Table 1 shows that almost clinical instructors sample age ranged from 25 to 29 $(62.90 \%)$ with mean and standard deviation of $30.645 \pm 4.595$ years. Their educational qualification were mainly bachelor nursing with mean and standard deviation experience of $6.612 \pm 2.212$. Most of them were married $62.90 \%$.

Table 2 shows that the total clinical teaching behaviors of clinical instructors as perceived by themselves was 90.19 representing $60.13 \%$ of maximum score. The highest maximum score was $62.72 \%$ for personality traits of clinical instructors as perceived by themselves and followed by student relationship, $61.46 \%$. On the other hand, the least maximum score was $58.87 \%$ for clinical instructors' teaching ability.

Table 3 shows that the overall mean of clinical instructors' teaching behaviors as assessed by undergraduate nursing students was 113.11 , representing 56.565 of the maximum. The teaching ability of clinical instructors had the highest score of $60.5 \%$ of maximum. And the relationship with students 
and clinical instructors' professional competency had relatively equal score $54.72 \%$ and $54.42 \%$ of the maximum respectively.

Figure 1 shows that the overall percentage of clinical instructors' perceptions for clinical teaching behaviors which was $60.13 \%$, i.e., higher than clinical teaching behaviors of clinical instructors as assessed by student $56.56 \%$ in the clinical settings.

Table 4 points to the highly statistically significant difference between clinical teaching behaviors of clinical instructors as perceived by themselves and those assessed by students $p<0.001$. In most of the table, the highest maximum score for both clinical instructors and students were reported for relationship with students 27.66 and 32.83 score, respectively. While the least mean score for personality traits of clinical instructors were 11.29 and 13.82 score.

Figure 2 shows the clinical instructors' ranking of factors which influence their behaviors in the clinical settings. In this figure, the majority of clinical instructors rank the professional competency of clinical instructors as the first factor that affects them, $41.9 \%$. While the students/teacher ratio $24.2 \% \%$ was reported as the least factor.

In table $\mathbf{5}$ shows Students' qualitative positive and negative comments for clinical teaching behaviors of their clinical instructors 
Table 1: Socio-demographic characteristics of clinical instructors $(n=62)$

\begin{tabular}{|c|c|c|}
\hline Characteristics & No. & $\%$ \\
\hline $\begin{aligned} \text { Age } & \\
& <25 \\
& 25-29 \\
& \geq 30\end{aligned}$ & $\begin{array}{l}3 \\
39 \\
20\end{array}$ & $\begin{array}{ll}4.84 & \\
62.90 & 32.26\end{array}$ \\
\hline Mean \pm SD & & \\
\hline $\begin{array}{c}\text { Educational qualification } \\
\text { Bachelor degree } \\
\text { Master degree }\end{array}$ & $\begin{array}{l}40 \\
22\end{array}$ & $\begin{array}{l}64.5 \\
35.5\end{array}$ \\
\hline $\begin{array}{c}\text { Years of experience } \\
\quad<5 \\
5-8 \\
>8\end{array}$ & $\begin{array}{l}14 \\
38 \\
10\end{array}$ & $\begin{array}{ll}22.58 & 61.29 \\
16.13 & \end{array}$ \\
\hline Mean \pm SD & & \\
\hline $\begin{array}{l}\text { Marital status } \\
\text { Single } \\
\text { Married }\end{array}$ & $\begin{array}{l}23 \\
39\end{array}$ & $\begin{array}{l}37.10 \\
62.90\end{array}$ \\
\hline
\end{tabular}

Table 2; Mean, standard deviation, and percentage of clinical instructors' teaching behaviors as perceived by themselves.

\begin{tabular}{|l|c|c|c|}
\hline Clinical teaching behavior & \multicolumn{2}{|c|}{ Clinical instructors (n=62) } & \multirow{2}{*}{$\%$ * } \\
\cline { 2 - 3 } & Max. score & Mean \pm SD & \\
\hline - Professional competency & 39 & $22.967 \pm 2.528$ & $58.87 \%$ \\
- Relationship with students & 45 & $27.661 \pm 2.996$ & $61.46 \%$ \\
- Teaching ability & 24 & $13.709 \pm 2.431$ & $57.08 \%$ \\
- Personality traits & 18 & $11.290 \pm 1.759$ & $62.72 \%$ \\
- Evaluation & 24 & $14.564+2.337$ & $60.66 \%$ \\
\hline Total & 150 & $90.193 \pm 4.601$ & $60.13 \%$ \\
\hline
\end{tabular}

\footnotetext{
${ }^{*}$ Percentages are calculated relative to maximum score
} 
Table 3: Mean, standard deviation, and percentage of clinical instructors' teaching behaviors as assessed by students

\begin{tabular}{|c|c|c|c|}
\hline \multirow[t]{2}{*}{ Clinical teaching behavior } & \multicolumn{2}{|c|}{ Students $(n=120)$} & \multirow{2}{*}{$\%$ * } \\
\hline & Max. score & Mean \pm SD & \\
\hline - Professional competency & 52 & $28.30 \pm 3.849$ & $54.42 \%$ \\
\hline - Relationship with students & 60 & $32.83 \pm 4.813$ & $54.72 \%$ \\
\hline - Teaching ability & 32 & $19.36 \pm 4.209$ & $60.5 \%$ \\
\hline - Personality traits & 24 & $13.82 \pm 3.424$ & $57.58 \%$ \\
\hline - Evaluation & 32 & $18.78 \pm 3.918$ & $58.69 \%$ \\
\hline Total & 200 & $113.11 \pm 10.89$ & $56.56 \%$ \\
\hline
\end{tabular}

- Percentages are calculated relative to maximum score

Table 4: Comparison Mean and standard deviation of clinical instructors' teaching behaviors as perceived by themselves with those assessed by students

\begin{tabular}{|c|c|c|c|c|}
\hline Behavior & Group & Mean $\pm S D$ & t-value & $p$-value \\
\hline - Professional & Clinical instructors 62 & $22.96 \pm 2.52$ & 11.253 & $<0.001^{*}$ \\
\hline competency & Students $\quad 120$ & $28.30 \pm 3.84$ & & \\
\hline - Relationship with & Clinical instructors 62 & $27.66 \pm 2.99$ & 8.854 & $<0.001^{*}$ \\
\hline students & Students & $32.83 \pm 4.81$ & & \\
\hline \multirow[t]{2}{*}{ - Teaching ability } & Clinical instructors 62 & $13.70 \pm 2.43$ & \multirow[t]{2}{*}{11.499} & \multirow[t]{2}{*}{$<0.001^{*}$} \\
\hline & Students & $19.36+4.20$ & & \\
\hline \multirow[t]{2}{*}{ - Personality traits } & Clinical instructors 62 & $11.29 \pm 1.75$ & \multirow[t]{2}{*}{6.602} & \multirow[t]{2}{*}{$<0.001^{*}$} \\
\hline & Students $\quad 120$ & $13.82 \pm 3.42$ & & \\
\hline \multirow[t]{2}{*}{ - Evaluation } & Clinical instructors 62 & $14.56 \pm 2.33$ & \multirow[t]{2}{*}{19.877} & \multirow[t]{2}{*}{$<0.001^{*}$} \\
\hline & Students $\quad 120$ & $18.78 \pm 3.91$ & & \\
\hline \multirow[t]{2}{*}{ Total } & Clinical instructors 62 & $90.19 \pm 4.60$ & \multirow[t]{2}{*}{19.877} & \multirow[t]{2}{*}{$<0.001^{*}$} \\
\hline & Students $\quad 120$ & $113.11 \pm 10.89$ & & \\
\hline
\end{tabular}

$X^{3}=143.419 \quad \mathrm{Df}=25$

- Statistically significant $P<0.001$ 


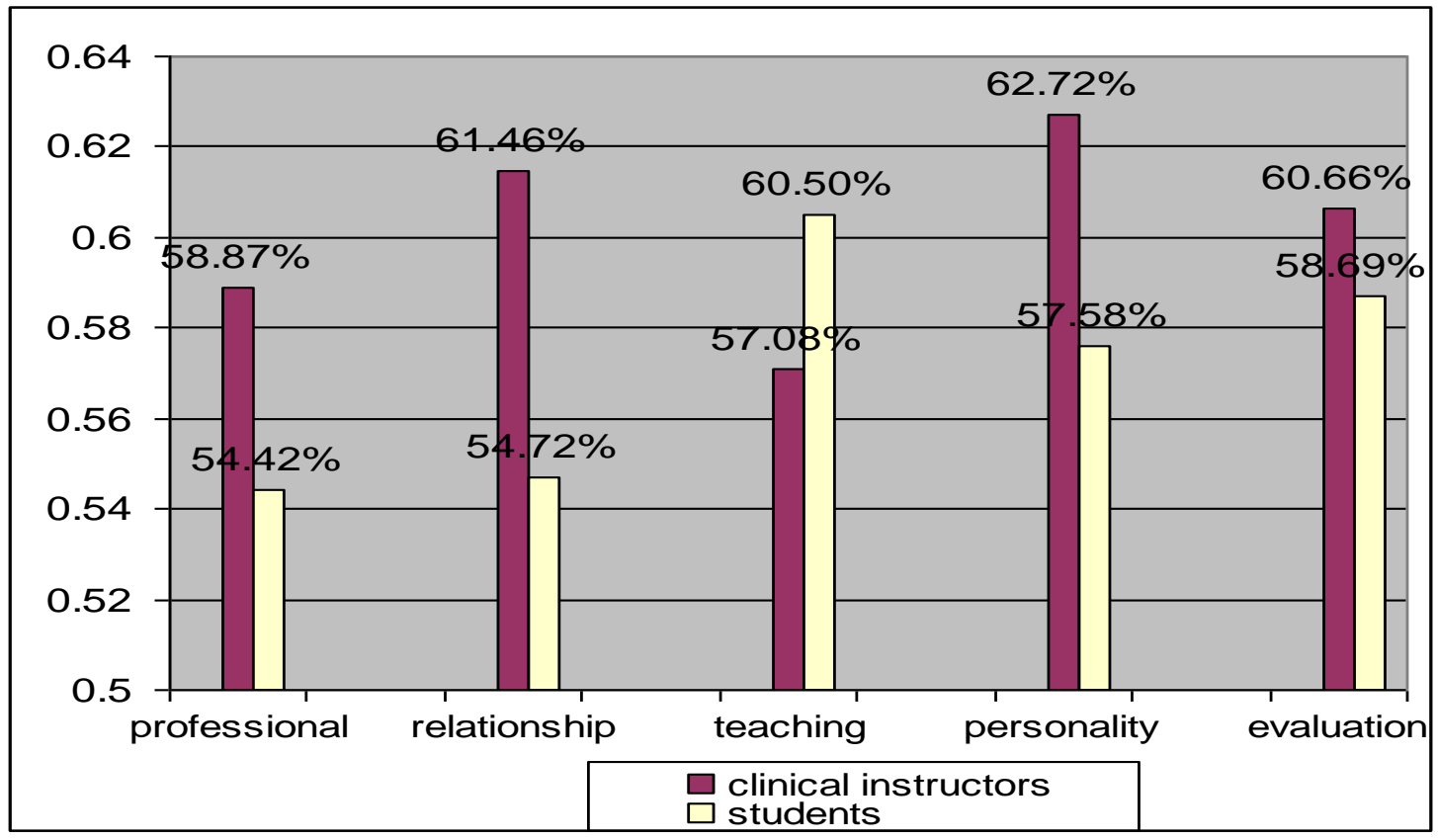

Figure 1: Comparison percentage of clinical instructors' teaching behaviors as perceived by themselves with those assessed by students.

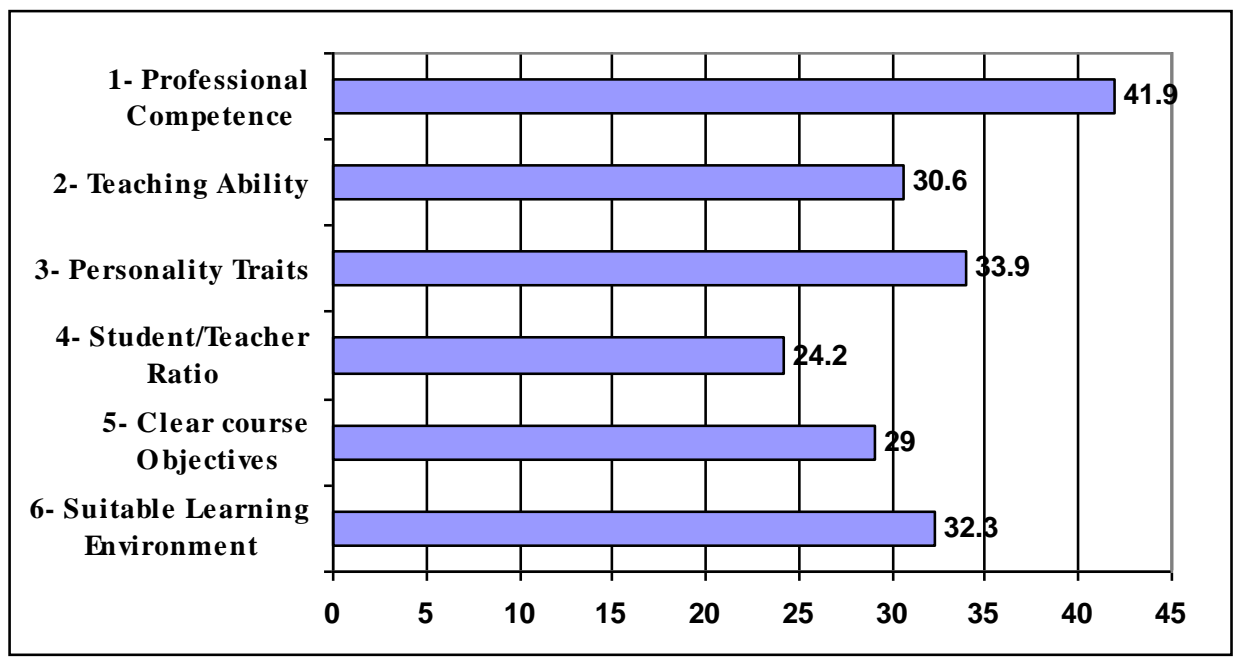

Figure 2: Percentage of the highest ranking factors that affecting clinical instructors' teaching behaviors in the clinical setting as perceived by themselves. 
Table 5: Students' qualitative positive and negative comments for clinical teaching behaviors of their clinical instructors.

\begin{tabular}{|c|c|c|}
\hline \multirow{2}{*}{$\begin{array}{l}\text { Clinical teaching } \\
\text { behaviors subscales }\end{array}$} & \multicolumn{2}{|l|}{ Clinical teaching behaviors } \\
\hline & Positive & Negative \\
\hline $\begin{array}{l}\text {-Professional } \\
\text { competence }\end{array}$ & $\begin{array}{l}\text {-As a source of information } \\
\text { - Able to communicate knowledge to } \\
\text { students } \\
\text { - Ask questions relevant to clinical } \\
\text { practice } \\
\text { - Well prepare, organize \& encourage } \\
\text { discussion in clinical conference }\end{array}$ & $\begin{array}{l}\text { - Difference among demonstrators } \\
\text { regards practice \& application } \\
\text { - Provides conflicting information } \\
\text { - Doesn't answer questions clearly \& } \\
\text { completely } \\
\text { - Doesn't encourage students' to be } \\
\text { creative in thinking }\end{array}$ \\
\hline $\begin{array}{l}\text {-Relationship with } \\
\text { students }\end{array}$ & $\begin{array}{l}\text { - Respects students' confidentiality } \\
\text { - Demonstrates flexibility as needed } \\
\text { - Able to adapt to change events as they } \\
\text { occurred } \\
\text { - Demonstrates patience in interpersonal } \\
\text { relationship }\end{array}$ & $\begin{array}{l}\text { - Doesn't permit freedom of } \\
\text { discussion \& venting of feeling } \\
\text { - Doesn't available often time to work } \\
\text { with students as situation arises in } \\
\text { the clinical settings } \\
\text { - Ask many questions }\end{array}$ \\
\hline - Teaching ability & $\begin{array}{l}\text { - Acts as essential asset to students' } \\
\text { learning by giving examples for } \\
\text { explanation } \\
\text { - Provides students with opportunities to } \\
\text { practice learning skills } \\
\text { - Realistic in expectation of students }\end{array}$ & $\begin{array}{l}\text { - Need to emphasize application } \\
\text { skills more for critical thinking \& } \\
\text { problem solving } \\
\text { - Doesn't give orientation at } \\
\text { beginning of the rotation } \\
\text { - Sometime spent to much time in } \\
\text { one subject } \\
\text { - Doesn't guide students in some topic }\end{array}$ \\
\hline - Personality traits & $\begin{array}{l}\text { - Is self control, confidence \& patient } \\
\text { - Open to discuses suggestions to } \\
\text { improve learning } \\
\text {-Shows enthusiasm for teaching } \\
\text { - Punctual on time } \\
\text { - Encourage team work }\end{array}$ & $\begin{array}{l}\text { - Doesn't treated student as adult } \\
\text { learners } \\
\text { - Doesn't always offered help when } \\
\text { needed } \\
\text { - Doesn't give us enough instructions } \\
\text { to do in clinical } \\
\text { - Doesn't motivate student }\end{array}$ \\
\hline - Evaluation & $\begin{array}{l}\text { - Giving positive feedback } \\
\text { - Made students' feel confident in his } \\
\text { performance } \\
\text { - Provides feedback at evaluation time }\end{array}$ & $\begin{array}{l}\text { - Reaming out students in front of } \\
\text { others } \\
\text { - Doesn't fair in the evaluation of the } \\
\text { students } \\
\text { - Doesn't provide feedback } \\
\text { throughout the rotation on students' } \\
\text { progress } \\
\text { - They are anxiety from evaluation }\end{array}$ \\
\hline
\end{tabular}




\section{DISCUSSION}

The clinical training is the heart of the nursing educational program and it remains the single most important resource in the development of competent, capable, and caring nurses. It also prepares the nurse students for their professional role. Changes in nursing education and health care, make the nurse educators' behaviors remains an area of longstanding dispute $\mathrm{e}^{(15,16)}$.

The present study aimed at comparing clinical instructors' teaching behaviors as perceived by themselves with those assessed by their students and there is a part of qualitative data were collected concerned with positive and negative behavior of clinical instructor. And also the clinical instructors asked to rank factors that affect their behavior in the clinical settings according to their priority.

The findings of the present study revealed that there were statistically significant differences on all clinical teaching behaviors subscales of clinical instructors as perceived by themselves and those assessed by nursing students. That means that students' expectations from clinical instructors are different from what their clinical instructors perceptions regard effective clinical teaching behaviors. This is agreed with Reeve's ${ }^{(10)}$ results who found that incongruence both students and faculty perceptions for best clinical instructors' clinical teaching behaviors in the clinical training.

Clinical instructors in the present study considered the professional competence as the first factor that affected their behaviors in the clinical settings. This is consistent with

Papp et at., ${ }^{(5)}$, Viverais-Desler \& Kutschke ${ }^{(17)}$ results that have shown professional competence as an important trait and important for effective teaching. This was emphasized by Clifford $^{(18)}$ who determined how experienced teachers define excellent teaching. These teachers identified professional competence as representing only one facet of excellence.

The students reported in the study that the source of information is a positive teaching behavior of clinical instructor. Similarly, the 
study carried out by Marie(19) on associated degree nursing students regarding their perception of the importance of clinical instructors' professional competence to be a good trainer for students in the clinical settings. He has described these behaviors as demonstrating clinical skills, taking responsibility for their own actions, serving as source of information, enabling trainees to care for patients, and demonstrating care for patients in a real situation.

In the present study, the students reported that there are differences among clinical instructors particularly during evaluation. One clinical instructor will place important on one aspect whereas another will place importance on something entirely different. This agreed with Elcigil \& Hatice ${ }^{(20)}$ who revealed that students have found certain differences in clinical skills among clinical instructors and that affect their learning as well.

Findings of the present study revealed that student-teacher relationship is an important behavior of the clinical instructor in the clinical training. That means that the clinical instructor can enhance relationship by encouraging students to ask questions, treating students equally, preparing thoroughly for class, showing patience, and learning students' names quickly. This is supported by Clifford $^{(18)}$ who emphasized that the teacher can be excellent and effective when maintaining a good interpersonal relationship with the students.

The students reported that they cannot always communicate easily with their clinical instructors and pointed out that they find their clinical instructors inaccessible in the clinical setting at most time. They report that the clinical instructors ask too many questions and that they felt bad when they could not answer these questions, so the student stop asking questions. Lee et al.,(21) found that students have singled out maintaining good relationships as the most important characteristic of an effective clinical instructor.

Students asserted that receiving positive-feedback makes students more confident of themselves. The feedback offers 
the student the opportunity to be aware of deficiencies and provides the chance for selfdevelopment. The question raised was, since the students asserted receiving positivefeedback, why the clinical instructor recommended that feedback be constructive and not destructive. This might be the effort to discover deficiencies and urge the students to correct these that causes educators to more frequently give the student negative feedback. This is the same view of many previous studies who have identified the importance of providing positive feedback to students on their clinical performance and assignment ${ }^{(22,23,24,25,)}$.

Lee et al.,(21) have indicated that offering feedback without hurting the student's feelings is among the most important characteristics of clinical instructor in the clinical setting. A qualitative study carried out by Papp et al.,(5), found that students express the need to be appreciated. In the same line, Evans \& Kelly (26) stated that not being able to offer constructive criticism is among the worst characteristics of the clinical instructor. Also,
Makarm ${ }^{(27)}$ emphasized that providing specific feedback enhanced students' abilities to provide quality care and to be accountable for their own professional growth.

In the present study, the students gave a comment that the clinical instructors don't encourage them to be creative in the clinical settings. This might be the fact that clinical instructors focus intensely on patient safety at the expense of the learner's freedom to experience creativity.

Findings of the present study revealed that there was a significant difference between clinical teaching ability of clinical instructors as perceived by themselves and those that were assessed by nursing students. The clinical instructors considered teaching ability of the clinical instructor as the second factor that affects their behavior. The percent of student assessment of the clinical instructors' teaching ability was $60.5 \%$. This is consistent with Wolf et al., $^{(14)}$ and Clifford(18) who has studied some characteristics related to clinical instructors' teaching ability and its influence on the effectiveness of their teaching, they 
concluded that enthusiasm for nursing and teaching, the ability to admit mistakes honestly, cooperation, patience, approachability, flexibility in the clinical area and the ability to provide opportunities for students to vent their feelings are the most personality traits of the clinical instructor.

Also in the present study the students reported that they are not sufficiently guided by their clinical instructors at all time in the clinical settings. The findings is agreed with O'Connor $^{(16)}$ and Andrea(28) who have suggested that much of the clinical instructor's time should be spent in supervising students as they carry out assignments in clinical area. This might be due to that clinical supervision keeps the clinical instructor alert to each student's progress in the clinical area, both in executing the assignment and demonstrating competence and skill in performing nursing activities with patients.

How the clinical instructor evaluates and gives feedback to the student in the clinical training is an important aspect of clinical education. At the Faculty of Nursing,
Mansoura University, all students mentioned that evaluation by the clinical instructor is the most serious problem they face in the clinical training. This may be due that students' anxiety of how they would be evaluated by clinical instructors led to focus on getting good grades and passing from their clinical training rather than concentrating on learning. This agreed with Elcigil and Hatice ${ }^{(20)}$ who found that, the clinical training stops being an area of learning and after a short time becomes just a place where the student to be graded. Viverais-Desler \& Kutschke ${ }^{(17)}$ found that nursing students considered "evaluation" as the most effective behavior among the different clinical educator behaviors and that fairness and constructive criticism were conducive to learning.

The clinical instructors At the Faculty of Nursing, Mansoura University consider the student/teacher ratio as a factor that affects their behavior in the clinical setting. Also students report that ratio between number of the students and clinical instructors number in the clinical setting affects the effective learning 
in the clinical teaching training. This means large number of students makes supervision difficult, crowds the clinical settings, and reduces learning opportunities. This is consistent with Kelly ${ }^{(15)}$ who found that large number of students makes difficult to students to practice and sometimes lead to graduate students with inadequate clinical experience.

The clinical instructor must be constantly aware of what their students consider as important teacher characteristics and practice, which fosters student learning in the clinical area. As clinical instructors become aware of those characteristics that are perceived as important, teaching strategies and attitudes may be reinforced, changed or developed in order to promote clinical education as an enjoyable experience rather than a frightening one for the nursing students.

\section{RECOMMENDATIONS}

Based on the findings of the present study, the following can be recommended:

1. Establish an orientation program for preparing of newly appointed clinical instructors about the principles of adult learning, how to bridge gap between theory and practice, how to assess students' needs, and evaluate students' performance.

2. Provide an opportunity for clinical instructors to discuss their clinical work, and examine clinical issues with faculty staff to create similarity clinical experience and foster the development of self-confidence.

3. More involvement of faculty staff in the clinical settings to provide guidance, support, and role model.

4. At the beginning of the clinical training, orientation session for the students and clinical instructors should be given about evaluation aspects, and duties and responsibilities of each other in the clinical training.

\section{REFERENCEES}

1. Lewin D. Clinical learning environment for student nurses: Key indices from two studies compared over a 25 year period. Nurse Education Practice. 2007;7:23846.

2. Tiwari DL, Rose Y, Chan C. Student learning in clinical nursing education: Perceptions of the relationship between assessment and learning nurse 
education. Nurs Educ Today. 2005;34(9):299-308 .

3. Andrew M, Roberts D. Supporting student nurses learning in and through clinical practice: The role of the clinical guide. Nurs Educ Today. 2003;23:47481.

4. Becker Mk, Neuwirth JM. Teaching strategy to maximize clinical experience with beginning nursing students. Jour Nurs Educ. 2002;41:89-91.

5. Papp I, Markanken M, Von-Bonsdroff M. Clinical environment as a learning environment: Student nurses' perceptions concerning clinical learning experiences. Nurs Educ Today. 2003;23:262-8.

6. Nahas VL, Nour V, Al-Nobani M. Jordanian undergraduate nursing students' perceptions of effective clinical teachers. Nurs Educ Today. 1999;19:639-48.

7. Merrbeau K. Cognitive coaching for nurse educator. J Nurse Educ.1992;31(4):188-90.

8. Walts T. Clinical teaching exercises and guidelines for health professionals who teach patient, train staff, and supervise students. Handbook of clinical teaching. $1^{\text {st }}$ ed. Edinburgh: 1990. p.224.

9. Duffy K, Watson H. An interpretive study of the nurse teacher's role in practice placement areas. Nurs Educ Today. 2001;21: 551-8.

10. Reeve M. Development of an instrument to measure effectiveness of clinical instructors. Jour Nurs Educ.1994; 33(1):15-20.

11. Beitz JM, Wieland D. Analyzing the teaching effectiveness of nursing faculty of ful-I and part-time generic BsN, and
RNBs nursing students. Jour Of Professional Nursing. 2005;21(1):32-45.

12. Siler BB, Kleiner C. Novice faculty: Encountering expectations in academia. Jour Nurs Educ. 2001;40(9):397-403.

13. Feldman KA, Paulsen MB. Faculty motivation: The role of a supportive teaching culture. In M.Theall (Ed.). San Francisco: Jussey-Ban; 71-78.

14. Wolf $Z$, Bender $P$, Beitz, Wieland D, Vito $K$. Strengths and weakness of nursing faculty as perceived by undergraduate and graduate nursing students. Jour Of Professional Nursing. 2004; 20:118-28.

15. Kelly C. Student's perceptions of effective clinical teaching revised. Nurs Educ Today. 2007;:1616/j.nedt 12.005.

16. O'Connor $A B$. Clinical instructions and evaluation. London; Tones and Bartelt; 2001.14-26.

17. Viverais-Desler G, Kutschke M. Students vatengs and opinions related to this importance of certain clinical teacher behaviors. Jour Of Continuing Education in Nursing. 2001;32:274-82.

18. Cillford $\mathrm{C}$. The clinical role of the nurse teacher: A conceptual frame work. Jour Advan Nurs. 1999;30(1):197-205.

19. Marie AA. Towards effective clinical teaching. Jour Advan Nurs. 2001; 12(4):505-13.

20. Elcigil A, Hatice Y. Determining problems experienced by student nurses in their work with clinical educators in Turkey. Nurs Educ Today. 2006;:10.1016

21. Lee WE, Cholowski K, Williams Ak. Nursing students and clinical educators perceptions characteristics of effective clinical educators in an Australian University, School of Nursing. Jour Advan Nurs. 2002;39:412-20. 
22. Caile G. Student and faculty perceptions of effective clinical instructors in AND program. Jour Nurs Educ. 2001;40(8):437-43.

23. Lofmark A, Wikblad K. Facilitating and obstructing factors for development of learning in clinical practice: A student perspective. Jour Advan Nurs. $2001 ; 34(1): 43-50$.

24. Oermann M. Differences in clinical experiences of AND and BsN students, Jour Nurs Educ. 1998;37(5):197-201.

25. Gaberson K, Oermann M. Evaluation and testing in nursing education, New York:1998. p.100.

26. Evans W, Kelly B. Pre-registration diploma student nurses stress and coping measures. Nurs Educ Today. 2004;24:473-82.

27. Makarm S, Dumit N, Adra M, Kassak K. Teaching effectiveness and learn clinical instructors. Jour Nurs Educ. 1994;33(1):15-20.

28. Andrea BO. Clinical instruction and teaching, clinical medicine. USA: Jons and Bartlett Publishers; 2003.201-209 
